p-ISSN: 2308-4944 (print) e-ISSN: 2409-0085 (online)

Year: 2017 Issue: 12 Volume: 56

Published: $30.12 .2017 \quad$ http://T-Science.org

SECTION 31. Economic research, finance, innovation, risk management.

\title{
THE CLASSIFICATION OF ANALYTICAL INDICATORS EVALUATION OF THE COMPANY'S FINANCIAL POTENTIAL
}

\begin{abstract}
The general concept, structure and concept of the financial potential assessment from the positions of the analysis of property and financial condition, as well as the efficiency of enterprise management are considered in the article. A special place to the formation of the financial potential of a number of Azerbaijani enterprises and to justify the classification of financial resources of enterprises is given. Methodical approaches to the definition of criteria and requirements for the assessment of the financial potential of the enterprise are outlined. Considerable attention to the analysis of the relationship between financial potential and the existing mechanism of enterprise management is paid. The classification of analytical indicators of financial potential assessment taking into account the effectiveness of the managerial activity of the subject is substantiated.

Key words: financial condition, financial resources, financial potential, solvency, liquidity, management activities, classification of financial indicators.

Language: Russian

Citation: Aliyeva AQ (2017) THE CLASSIFICATION OF ANALYTICAL INDICATORS EVALUATION OF THE COMPANY'S FINANCIAL POTENTIAL. ISJ Theoretical \& Applied Science, 12 (56): 151-156.

Soi: http://s-o-i.org/1.1/TAS-12-56-24 Doi: crostef https://dx.doi.org/10.15863/TAS.2017.12.56.24

\section{КЛАССИФИКАЦИЯ АНАЛИТИЧЕСКИХ ПОКАЗАТЕЛЕЙ ОЦЕНКИ ФИНАНСОВОГО ПОТЕНЦИАЛА ПРЕДПРИЯТИЯ}

Аннотация: В статье рассмотрены общее понятие, структура и концепция оценки финансового потенциила с позиций анализа имущественного и финансового состояния, а также эффективности управления предприятием. Особое место отведено вопросам формирования финансового потенциала ряда предприятий Азербайджана и обоснования классификации финансовых ресурсов предприятий. Изложены методические подходы $\kappa$ определению критериев и требований к оценке финансового потенциала предприятия. Значительное внимание уделено анализу взаимосвязи финансового потенциала и существующего механизма управления предприятием. Обосновывается классификация аналитических показателей оценки финансового потенциала с учётом результативности управленческой деятельности субъекта.

Ключевые слова: финансовое состояние, финансовые ресурсы, финансовый потенциал, платёжеспособность, ликвидность, управленческая деятельность, классификация финансовых показателей.
\end{abstract}

\section{Introduction}

Реализация субъекта повышения конкурентоспособности экономики и социального благосостояния на основе устойчивого экономического развития, определенные стратегической Дорожной картой по основным секторам национальной экономики предполагают эффективное использование финансово-экономического потенциала, созданного в предыдущие годы. Основным условием обеспечения развития базовых отраслей материального производства (нефтегазодобывающей, пром-стройматериалов, металлургической, производства электрооборудования, машиностроительной и сельского хозяйства) в соответствии с основными целями и задачами Стратегической Дорожной Карты является наличие необходимого 
финансового потенциала у предприятий указанных отраслей [1].

\section{Materials and Methods}

В финансовой литературе для обозначения финансового потенциала субъекта используются понятия «финансовые ресурсы» и «финансовое состояние». Л.Н.Павлова определяет финансовые ресурсы как собственные источники, остающиеся в распоряжении предприятия после выполнения текущих обязательств по расчетам и направляемые на финансирование расширенного производства [2]. По мнению И.Т.Балабанова, денежные средства, имеющиеся в распоряжении предприятия, составляют его финансовые ресурсы [3]. Исследование проблем финансового анализа и управления капиталом, проведенное В.В.Ковалевым имеет исключительное значение для изучения структуры источников финансирования современного предприятия, работающего в условиях рынка [4;5]. Автор, рассматривая повышение экономического потенциала предприятия, основным фактором деловой активности, под внутренними и внешними источниками финансирования понимает соответственно собственные к привлечению средства. Р.А.Искендеров считает, что централизованные и децентрализованные фонды денежных средств, обеспечивающие финансовые нужды деятельности предприятия образуют его финансовые ресурсы [6].

Как видно, финансовый потенциал рассматривается экономистами как совокупность финансовых ресурсов, находящихся в распоряжении предприятий, но, в то же время, вопросы определения состава финансовых ресурсов, а именно: относятся не заемные средства или централизованные фонды денежных средств к финансовым ресурсам конкретного предприятия, остаются открытым. По нашему мнению, необходимо учитывать следующие критерии и требования в оценке финансового потенциала предприятия, осуществляющего производственнокоммерческую деятельность:

> финансовый потенциал характеризуется обеспеченностью финансовыми ресурсами, необходимыми для нормального функционирования предприятия и его способностью своевременно производить платежи, финансировать свою деятельность в условиях рыночной системы;

$>$ элементы (ресурсы) образующие состав финансового потенциала создаются в денежной форме и имеют денежную размерность;

$>$ количественные показатели финансового потенциала предприятия отражаются в финансовой отчётности; формирование и использование финансовых ресурсов считаются результатом управления хозяйственно - финансовой деятельности и должны подтверждаться отчетом об управлении финансовыми ресурсами предприятия;

$>$ определенная сумма денежных средств, чтобы быть отнесенной к финансовому потенциалу должна принадлежать предприятию, которое в правовом отношении имеет возможность осуществлять фактическое владение денежными ресурсами, в том числе и заемными средствами.

C учетом указанных критериев следует относить в состав финансовых ресурсов предприятия банковские кредиты, бюджетные субсидии и ссуды, которые находясь в распоряжении предприятия обслуживают процесс хозяйственно деятельности.

Таким образом, под финансовым потенциалом следует понимать совокупность собственных и привлеченных финансовых ресурсов, обеспечивающих выполнение обязательств по платежам и расчетам, связанных с осуществлением хозяйственно - финансовой деятельности, регламентируемой уставом предприятия.Результативность хозяйственнофинансовой деятельности в значительной степени определяется анализом показателей годового отчета, обеспечивающих достоверное представление информации о финансовом состоянии предприятия. Основная цель такого анализа сводится к определению формы финансирования хозяйствующего субъекта, эффективности его деятельности и платежеспособности. По результатам оценки финансового состояния определяют, сумеет ли предприятие в текущей период выполнить свои обязательства перед третьими лицамиакционерами, инвесторами, кредиторами, покупателями, продавцами и др., или ему угрожают финансовые затруднения.

В экономической литературе наибольшее распространение получила концепция оценки финансового потенциала с позицией анализа имущественного положения предприятия и его финансового состояния. После ознакомления с мнениями В.В.Ковалева и Л.Н.Павловой высказанными ими в трудах, посвященных проблемам анализа финансового состояния, автор настоящей работы делает вывод о необходимости учета результативности управления финансовыми ресурсами (финансового менеджмента), как фактора, определяющего достаточности финансового потенциала предприятия в системе финансового анализа. Правильность такого подхода продиктована современными требованиями усиления роли 
эффективной структуры управления и целенаправленного человеческого капитала в финансовом оздоровлении убыточных предприятий республики.

Определение финансового потенциала предприятия должно основываться на:

$>$ оценке качественных изменений в имущественном положении предприятия;

$>$ оценке изменений в финансовом состоянии;

$>$ оценке эффективности управления финансовыми ресурсами.

Значение оценки качественных показателей в имущественном положении для определения финансового потенциала предприятия заключается в том, что находящиеся в распоряжении предприятия основные средства, оборотные средства и трудовые ресурсы составляют материальные и человеческие факторы хозяйственно-финансовой деятельности, в процессе которой создаются денежные доходы субъекта. Имущественное положение предприятия обычно определяется на основе данных баланса.

Для оценки качественных изменений в имущественном положении и степени их действенности представляется необходимым использования таких показателей как, дельный вес активной части основных средств, коэффициент их полезности, удельный вес быстрореализуемых активов, объем долгосрочных обязательств, структура оборотных производственных запасов, оборачиваемость оборотных средств, мобилизация или иммобилизация оборотных средств. Используя приведенные формы обязательной финансовой отчетности ЗАО «Бакинский метрополитен», ЗАО «Италдизайн» и ООО «НэманИКФ» было определено, что удельный вес основных средств в активах Бакинского метрополитена составил 96.2 \%б Италдизайна - 6.8 \% и Нэман ИКФ - 30.7 \% в 2015 г. С учетом этих показателей нетрудно можно было бы определить различные масштабы финансирования основного капитала по предприятиям. Только по Бакинскому Метрополитену неоплаченный убыток к началу 2015 г. составил 311,8 млн. манат. Данный свидетельствуют о том, что осуществление капитальных вложений по метрополитену за счет собственных средств не соответствуют его финансовому потенциалу. По другим предприятиям вопросы финансирования основного капитала в рамках индивидуального кругооборота капитала могут решаться без особых осложнений.

Основное направление оценки финансового потенциала заключается в анализе финансового состояния предприятия с позиций его платежеспособности и финансовой устойчивости.
Используя абсолютные и относительные показатели можно определить степень ликвидности и финансовой устойчивости предприятия. Согласно действующим правилам платежеспособность предприятия показывает способность предприятия рассчитываться по своим внешним обязательствам. Отсюда ясно, что предприятие платежеспособным становится, если сумма оборотных активов (товарноматериальных запасов, денежной наличности, дебиторской задолженности и других активов) больше или равна его внешней задолженности сумма оборотных активов по Бакинскому метрополитену составила 92.8 млн. манат в 2014 г. и 79.6 млн. ман., а внешние обязательства составили соответственно 213.7 млн. ман. и 94.9 млн. ман. Сопоставляя эти данные можно увидеть, что внешняя задолженность Бакинского метрополитена была больше его оборотных активов в 2014 г. на сумму 120.9 млн. ман. и 15.3 млн. ман. в 2015 г. Таким образом, сравнивая текущие активы с внешними обязательствами, к началу 2016 г. Бакинский метрополитен можно называть неплатежеспособным предприятием.

Общепринято, что в условиях рыночного хозяйства предприятие с высоким удельным весом оборотного капитала считается наиболее надежным партнером, ибо оно имеет возможность выполнить свои финансовые обязательства в относительно короткий период времени. С этой точки зрения Италдизайн оказывается в наиболее благоприятном положении ввиду того, что из общей суммы его активов в 13.1 млн. ман. более $92 \%$ приходится на долю быстро ликвидных оборотных активов. Оценка ликвидности предприятия в качестве одного из важнейших критериев финансового положении позволяет точно определить способность предприятия платить по своим краткосрочным обязательствам.Для определения достаточности оборотных средств для веденияхозяйственной деятельности и своевременного погашения срочных обязательств предприятия, используемый нами коэффициент ликвидности был рассчитан на основе данных баланса по анализируемым предприятиям и получены следующие результаты: Бакинский метрополитен: 2,424; Италдизайн: 3,018 и Неман ИКФ: 3,432 .

С учетом того, что по общепринятой методике этот коэффициент должен иметь значение не менее 2, то полученные нами показатели свидетельствуют об удовлетворительной структуре баланса анализируемых предприятий.Исследование показывает, что способность предприятия выполнить свои обязательства оценивается и с помощью коэффициента обеспеченности собственными средствами, характеризующего 
наличие собственных оборотных средств, необходимых для поддержания его финансовой устойчивости. Следует признать, что нормально работающие предприятия действуя по направлению повышения коэффициента текущей ликвидности одновременно создают условия для повышения коэффициент обеспеченности собственными средствами.

Финансовый потенциал представляет собой совокупность денежных ресурсов, обеспечивающих финансирование расходов по осуществлению производственно-коммерческой деятельности, предусмотренной уставом предприятия. В составе этих ресурсов объектом управления становятся уставный капитал, выручка от реализации, прибыль ли убыток, децентрализованные фонды денежных средств (фонд заработной платы, амортизационный фонд, резервный фонд, фонды накопления и потребления).При недостаточности денежных средств в распоряжении предприятия для финансирования инвестиционного проект решается вопрос о привлечении заемного капитала.

В практике действующих предприятий распространены следующие варианты привлечения заемных средств:

$>$ получение финансовых ресурсов путем выпуска облигаций акционерных обществ (в настоящее время эмитируются облигации государственной нефтяной компании - SOCAR);

$>$ приобретение долгосрочного и краткосрочного кредита в коммерческих банках, в государственных не банковских кредитных организациях; лизинга;

$>$ финансирование путем получения

$>$ привлечение средств из внутренних источников.

Теоретический анализ источников финансирования предприятий показывает, что финансовый потенциал предприятия имеет свою внутреннюю структуру, регламентируемую хозяйственным и налоговым законодательством. Несмотря на наличие единой для всех субъектов страны правовой базы, экономисты по-разному определяют структуру финансовых ресурсов предприятия. Например, В.Я.Горфинкель и В.А.Швандра к источникам собственных средств относят уставный капитал, резервный капитал, создаваемый за счет отчислений из прибыли, фонды накопления и социальной сферы, создаваемые за счет отчислений из прибыли, нераспределённую прибыль Л.Н. Павлова круг финансирования капитальных вложений ограничивает финансовыми средствами предприятий, фондом накопления, бюджетными предприятиями и целевым финансированием [7;2]. Как видно, авторами не учтены возможности использования таких децентрализованных фондов, как амортизационный фонд, фонд зарплаты, создаваемых в процессе распределения выручки от реализации продукции в качестве самостоятельных финансовых источников текущих и капитальных IIIзатрат на предприятии. Считаем, что в отрыве от норм действующего бухгалтерского и налогового законодательства разработка классификации финансовых ресурсов предприятия невозможна.

Исходя из вышеизложенного можно дать следующую классификацию финансовых ресурсов предприятия:

I. Собственные средства: уставный капитал, добавочный капитал, резервный капитал, нераспределенная прибыль (непокрытый убыток).

II. Заемные средства: долгосрочные кредиты, долгосрочные займы, краткосрочные кредиты, краткосрочные займы.

III. Привлеченные средства: кредиторская задолженность по товарам, работам и услугам; по расчетам с бюджетом и внебюджетными фондами; по оплате труда; с другими кредиторами.

Привезенная классификация служит ориентиром для регулирования процесса финансирования предприятия и принятия управленческих решений по обеспечению субъекта денежными ресурсами. Процесс оценки финансового потенциала предприятия завершается анализом эффективности управления финансовыми ресурсами [8;9;10;11]. Результативность финансовых операций по мобилизации и целенаправленному использованию денежных доходов предприятий, действующих в условиях рыночных отношений в значительной степени зависит от правильного управления предприятием и прежде всего, его финансовый деятельностью $[12 ; 13 ; 14]$. При оценке работы предприятия, его хозяйственнофинансовой деятельности учет показателей, отражающих управленческую деятельность менеджера становится неизбежным. Представляется, однако, невозможным определить формирование эффективной структуры управления предприятием, опасности, существующие для хозяйственно-финансовой деятельности, отклонения от установленных стандартов, результативность использования человеческого капитала на основе анализа сведений финансовой отчетности предприятий, освещенных в периодической печати и в Интернете. Отметим, что эффективность деятельности предприятий в условиях рыночной экономики непосредственно зависит от результатов осуществления функций 
менеджмента планирования, организация, мотивация, координирования и контроля.

Важнейшей составной частью общей системы руководства предприятием является управление персоналом, осуществляемым с целью разработки кадровой политики и принятия управленческих решений по управлению трудовыми ресурсами на предприятии. Анализируя состояния организации работы на промышленных предприятиях республики, можно увидеть, что в $35 \%$ предприятий проблема заключается в неэффективности структуры управления предприятиями и организации работы сотрудников, что характеризуется отсутствием системы диагностики управления в рамках предприятия.

Таким образом, деятельность по управлению предприятием и соответствующими подразделениями наряду с хозяйственно финансовой деятельностью является самостоятельной сферой функциональной деятельности единого хозяйствующего субъекта, без которой не может функционировать не одна организация. При действующей системе оценки финансового потенциала предприятий используются сведения баланса и отчета о прибыли предприятия (маркетинг, производство, реализация и финансы) без учета результатов управленческой деятельности субъекта. Считаем, что показатели, характеризующие управленческую деятельность руководства предприятия.

С учетом того, что финансовый потенциал предприятия отражается в его бухгалтерской отчетности целесообразно предположить следующую классификацию показателей для оценки финансового потенциала по следующим направлениям:

Первое направление - оценка качественных изменений в имущественном положении предприятия и рекомендуемые аналитические показатели первого направления:

1) Стоимость основных средств.

2) Коэффициент полезности основных средств.

3) Объем капитальных вложений.

4) Стоимость нематериальных активов.

5) Удельный вес основных средств в активах предприятия.

6) Стоимость товарно-материальных ценностей.

7) Коэффициент оборотности средств оборота.

Второе направление - оценка состояния управления финансовыми ресурсами и рекомендуемые аналитические показатели второго направления:

1) Сумма собственных средств.
2) Сумма заемных средств.

3) Сумма привлеченных средств.

4) Объем оборотного капитала.

5) Удельный вес оборотных средств в активах предприятия.

6) Коэффициент абсолютной ликвидности.

7) Коэффициент промежуточной ликвидности.

8) Коэффициент текущей ликвидности.

9) Коэффициент платёжеспособности.

10)Коэффициент обеспеченности собственными средствами.

11)Коэффициент финансовой устойчивости.

12)Прибыль.

13)Убыток.

14)Рентабельность.

15)Непогашенные кредиты и долги.

16)Просроченная дебиторская и кредиторская задолженность.

17)Непогашенные векселя.

18)Фонд заработной платы.

19)Амортизационный фонд.

20)Остаток денежных средств по операционным, инвестиционным и финансовым деятельности.

Третье направление - оценка состояния управления финансовыми ресурсами и рекомендуемые аналитические показатели третьего направления:

1) Управленческие решения по целям и их исполнение.

2) Управленческие решения по результатам и их исполнение.

3) Управленческие решения по особым ситуациям и их исполнение.

4) Управленческие решения по активизации деятельности персонала.

5) Применение метода менеджмента, основанного на искусственном интеллекте.

6) Кадровые решения и их исполнение.

7) Сведения об организации менеджмента по функциональным отраслям деятельности предприятия.

\section{Conclusion}

Предложенная классификация аналитических показателей оценки финансового потенциала по трем направлениям, тесно взаимодействующим и переплетающимся друг с другом, с точки зрения предмета и объекта принятия управленческих решений имеет важное теоретическое и практическое значение. Из всего набора рекомендуемых выше показателей для комплексной оценки финансового потенциала предприятия достаточно двух показателей: коэффициент текущей ликвидности и коэффициент обеспеченности собственными средствами. Показатели финансового потенциала должны быть такими, чтобы все

ISPC Generalization of scientific results, 


\begin{tabular}{l|lr|ll|ll} 
& ISRA (India) & $=\mathbf{1 . 3 4 4}$ & SIS (USA) & $=\mathbf{0 . 9 1 2}$ & ICV (Poland) & $=\mathbf{6 . 6 3 0}$ \\
Impact Factor: & ISI (Dubai, UAE) $=\mathbf{0 . 8 2 9}$ & PUHL (Russia) $=\mathbf{0 . 2 0 7}$ & PIF (India) & $=\mathbf{1 . 9 4 0}$ \\
& GIF (Australia) & $=\mathbf{0 . 5 6 4}$ & ESJI (KZ) & $=3.860$ & IIBI (India) & $=\mathbf{4 . 2 6 0}$ \\
& JIF & $=\mathbf{1 . 5 0 0}$ & SJIF (Morocco) & $=\mathbf{2 . 0 3 1}$ & & \\
\hline
\end{tabular}

заинтересованные лица, связанные с предприятием хозяйственными договорами, могли бы своевременно определить, насколько надежно предприятие как партнер в этих связях, а значит, принять решение об экономической целесообразности продолжения договорных отношений.

\section{References:}

1. (2016) Strategicheskiye dorozhnyye karty po perspektivam natsional'noy ekonomiki Azerbaydzhanskoy Respubliki. Utverzhdeno Ukazom Prezidenta Azerbaydzhanskoy Respublikiot 6 dekabrya 2016 goda.

2. Pavlova L.N. (1998) Finansy predpriyatiy. M., Finansy, 1998.

3. Balabanov I.T. (1999) Osnovy finansovogo menedzhmenta. M., Finansy i statistika, 1999.

4. Kovalev V.V. (1997) Finansovyy analiz. Upravleniye kapitalom. Vybor investitsiy. Analiz otchetnosti. M., Finansy i statistika, 1997.

5. Kovalev V.V. (2004) Vvedeniye v finansovyy menedzhment. - Moscow, Finansy i statistika, 2004. $-768 \mathrm{p}$

6. Iskenderov R.A. (2007) Finansy predpriyatiy. Baku, Izd-vo Azerbaydzhanskogo Tekhnicheskogo Universiteta, 2007.

7. (1998) Ekonomika predpriyatiya: Pod redaktsiyey professora V.YA. Gorfinkelya, prof. V.A.Shvandra. M., Banki i birzhi, YUNITI, 1998.
8. Salpagarov M.A. (2010) Sovershenstvovaniye mekhanizma finansovogo ozdorovleniya predpriyatiy. Diss.kand. ekon. nauk. Moscow, 2010.-163 p.

9. Kovaleva A.M., Lapusta M.G., Skamay L.G. (2000) Finansy firmy: Moskva, INFRA-M, 2000. - $416 \mathrm{p}$.

10. Ostapenko V.V. (2004) Finansy predpriyatiy: Moscow, Omega-JI, 2004. -304 p.

11. (2000) Finansovyy menedzhment: teoriya i praktika: 5-ye izd., pererab. i dop. - Moscow, Perspektiva, 2000. - $656 \mathrm{p}$.

12. (2003) Finansovyy menedzhment. Moscow, ID FBK-PRESS, 2003.- $213 \mathrm{p}$.

13. (2015) Rick-menedzhment $\mathrm{v}$ antikrizicnom upravlenii // Teoriya antikrizicnogo menedzhmenta. Moscow, 2015. - Gl. 3.4.- p. 178-193.

14. Glukhova D.V. (2015) Sovershenstvovaniye mekhanizma antikrizisnogo finansovogo upravleniya $\mathrm{v}$ organizatsiyakh. Diss. kand. ekon. nauk. Stavropol' - 2015. -218 p. 